\title{
Qualidade da água para irrigação na microbacia do Coqueiro, Estado de São Paulo ${ }^{1}$
}

\author{
Renato A. M. Franco ${ }^{2} \&$ Fernando B. T. Hernandez ${ }^{3}$
}

\begin{abstract}
RESUMO
O objetivo deste estudo foi analisar as propriedades físico-químicas da água para fins de irrigação na microbacia do Coqueiro (SP), afluente da margem direita do rio São José dos Dourados, localizado entre os municípios de Jales, São Francisco, Palmeira d'Oeste e Dirce Reis, SP. As amostras de água foram coletadas em cinco pontos georreferenciados, ao longo do córrego, e analisadas mensalmente durante um ano (períodos de 2006 a 2007) os parâmetros sólidos suspensos e dissolvidos, turbidez, condutividade elétrica, pH, cálcio, magnésio, dureza e ferro total. Os resultados mostraram que os parâmetros físico-químicos apresentaram classificação de baixo a médio potencial de dano ao sistema de irrigação, exceto o ferro total, que ficou na classificação de médio a alto potencial de dano por obstrução aos sistemas de irrigação localizada.
\end{abstract}

Palavras-chave: assoreamento, bacia hidrográfica, monitoramento

\section{Water quality for irrigation in the micro watershed of the Coqueiro stream, São Paulo State, Brazil}

\begin{abstract}
The aim of this study was to evaluate the physico chemical characteristics of water quality for irrigation purposes in the micro basin of Coqueiro, a tributary on the right bank of the São José dos Dourados river, located between the municipalities of Jales, São Francisco, Palmeira d'Oeste and Dirce Reis, in the state of São Paulo, Brazil. Water samples were collected at five geo-referenced points along the stocam and analysed monthly for one year. The parameters analysed were: suspended and dissolved solids, turbidity, electrical conductivity, $\mathrm{pH}$, calcium, magnesium, hardness and total iron. The result showed that the physico chemical parameters had the classification of medium potential for damage to the irrigation system, except total iron, which was classified as having medium to high potential for damage by clogging for localized irrigation systems.
\end{abstract}

Key words: silting, watershed, management

Pesquisa financiada pelo FEHIDRO Empreendimento SJD.

Biólogo e Doutorando em Sistemas de Produção na UNESP Ilha Solteira. Rua Passeio Sobral 424, Fone: (18) 3742-4008. E-mail: bioramfranco@yahoo.com.br

3 Departamento de Fitossanidade, Engenharia Rural e Solos/UNESP, CP 34, CEP 15385-000, Ilha Solteira, SP. Fone: (18) 3743-1180. E-mail: fbthtang@agr.feis.unesp.br 


\section{INTRODUÇÃO}

Os ecossistemas aquáticos continentais são utilizados no Brasil e no mundo como recursos disponíveis para a sociedade, com significado ecológico, econômico e social (Tundisi et al., 2006). As finalidades de uso são múltiplas, entre as quais se destacam o abastecimento público de água, a geração de energia elétrica, a irrigação, a aqüicultura, a dessedentação animal e a harmonia paisagística. Nos últimos anos os recursos hídricos vêm sendo modificados por ação antrópica, resultando em prejuízo na qualidade e disponibilidade de água, sendo notória a necessidade crescente do monitoramento das alterações na qualidade de água, de forma a não comprometer seu aproveitamento múltiplo e minimizar os impactos negativos do ambiente. (Braga et al., 2006)

No Estado de São Paulo as bacias hidrográficas foram divididas em 22 Unidades de Gerenciamento de Recursos Hídricos (UGRHI). A bacia hidrográfica do São José dos Dourados, pertencente à UGRHI - 18, localizada na região noroeste do Estado, é composta de 25 municípios com atividades econômicas voltadas para os setores da agroindústria. Os principais produtos do setor primário nesta bacia hidrográfica são citros, café, banana, uva e agropecuária, sendo que todos os municípios desta UGRHI têm a cultura da braquiária como principal cultura (CETESB, 2005).

A microbacia do córrego do Coqueiro, que compreende os municípios de Jales, São Francisco, Palmeira D’Oeste e Dirce Reis, cujas atividades predominantes são a agropecuária, a agricultura com lavouras permanentes e temporárias, destacando-se a fruticultura irrigada (abacate, banana, coco-da-baia, citros, mamão, manga, goiaba, maracujá e uva) e a pastagem extensiva com grande potencial erosivo, conta ainda com outras atividades, como o fornecimento de água para abastecimento dos municípios de Palmeira d'Oeste e Marinópolis - SP.

Com déficits hídricos prolongados na região, ao longo de oito meses por ano, considerada a maior evapotranspiração do Estado de São Paulo e suscetível a veranicos (Hernandez et al., 2003), o desenvolvimento sócieconômico desta bacia hidrográfica está condicionada a implantação de sistemas de irrigação, de modo a minimizar riscos de perda de produtividade, além de flexibilizar as épocas de plantio e escolha de culturas a serem implantadas. Todavia, o uso dessa água para fins de irrigação pode conflitar com o uso para o abastecimento urbano e o uso múltiplo pode ser comprometido pela dependência dos recursos hídricos superficial, pelo desmatamento, pela erosão e o conseqüente assoreamento dos corpos d’água.

A bacia hidrográfica do São José dos Dourados se enquadra na categoria de alta criticidade e o impacto da erosão nos recursos hídricos é considerado muito crítico em razão de apresentar predomínio de áreas com alta suscetibilidade e de maior concentração no número de feições erosivas lineares. Segundo o Relatório da CETESB (2005), os municípios de São Francisco e Dirce Reis se apresentam com criticidade média e os municípios de Jales e Palmeira d'Oeste estão na categoria de criticidade alta em relação ao processo erosivo.

Em relação à vegetação natural remanescente nos muni- cípios citados, apresentam baixa porcentagem de áreas preservadas (SEMA, 2006), reflexo do uso e ocupação da bacia hidrográfica. Essas alterações ambientais causam inúmeros impactos principalmente nos recursos hídricos superficial, pois os rios de fluxo unidirecional geram transporte horizontal dos materiais (sedimentos, nutrientes etc) presentes na água, em geral de origem alóctone e provenientes das áreas adjacentes (agricultura e área urbana) ou de regiões superiores (sentido nascente-foz) que podem comprometer a qualidade da água do rio, especialmente para fins de irrigação e um recurso natural finito cuja qualidade e disponibilidade de água vem piorando nos últimos anos, em decorrência da falta de uma política de gerenciamento.

Considerando a importância do córrego do Coqueiro objetivou-se, com este trabalho, monitorar a qualidade de água para fins de irrigação, utilizando-se as variáveis físicas e químicas que, por sua vez, indicam as alterações ocorridas na microbacia, sejam de origem antrópicas ou natural e que podem comprometer o sistema de irrigação.

\section{MATERIAL E MÉTODOS}

\section{Localização e caracterização da área de estudo}

Este trabalho foi desenvolvido na microbacia do Córrego do Coqueiro, com área aproximada de $199,3 \mathrm{~km}^{2}$, localizada na região noroeste do Estado de São Paulo, que abrange os municípios de Jales, São Francisco, Palmeira d'Oeste e Dirce Reis. Esta microbacia é integrante da Unidade de Gerenciamento de Recursos Hídricos do Rio São José dos Dourados (UGRHI-18) e se situa entre as coordenadas geográficas de $20^{\circ} 15^{\prime} 25^{\prime \prime}$ Sul e $50^{\circ} 34^{\prime} 44^{\prime \prime}$ Oeste e $20^{\circ} 31^{\prime} 45^{\prime \prime}$ Sul e $50^{\circ} 44^{\prime} 25^{\prime}$ ' Oeste, com altitude entre 334 a $492 \mathrm{~m}$.

A vegetação originalmente predominante na bacia é a floresta estacional (semidecidual e decidual) estando, em sua maioria, fragmentada e degradada, por se situar em áreas que passaram por grandes transformações econômicas (CETESB, 2005). Os fragmentos estão localizados ao longo de cursos d'água e são considerados floresta estacional semidecidual ribeirinha com influência fluvial sazonal (Rodrigues, 2000), sendo 1,7\% o valor médio de vegetação natural remanescente nos municípios por onde passa o córrego do Coqueiro (CETESB, 2005).

A classificação climática para a região, segundo Köeppen, é o subtropical úmido, Cwa, com inverno seco e ameno e verão quente e chuvoso (Pereira et al., 2002).

\section{Pontos de coleta e atributos analisados}

Para a avaliação da qualidade de água do córrego foram georreferenciados, ao longo do leito principal, cinco pontos para a coleta e análise da água, as quais foram realizadas em intervalos de aproximadamente um mês entre o período de 26/ 10/2006 a 11/10/2007, totalizando 13 amostras de água por cada ponto. Nas coletas dos meses de novembro e dezembro de 2006, choveu três dias antes da coleta; no ano de 2007 as amostras dos meses de janeiro, março, maio, julho e setembro tiveram influência da precipitação, pois um dia antes das coletas ocorreu chuva na área de contribuição da microbacia. 
O Córrego do Coqueiro está inserido na Bacia Hidrográfica do rio São José dos Dourados; trata-se de um dos afluentes da margem direita, com 29,4 km de extensão da nascente até a foz deste rio. Os pontos de coleta foram assim distribuídos, ao longo do córrego: ponto 1 (S 20 18’ 53,7”; W $\left.50^{\circ} 38^{\prime} 17,5^{\prime \prime}\right)$ a $6,0 \mathrm{~km}$ da nascente, passando por pequenas propriedades que abrangem o município de Jales; ponto 2 (S $20^{\circ} 22^{\prime} 37,0$ ”; W 5040' 37,7”), distante $14,1 \mathrm{~km}$ da nascente, situado no município de São Francisco, trecho de pequenas e grandes propriedades agrícolas, com predomínio de pecuária extensiva; ponto 3 (S 20²4' 23,4”; W 50 40’ 51,8”), localizado no município de Palmeiras d'Oeste, próximo à Estação de Tratamento de Água da Sabesp com distância de 17,4 km da nascente; ponto 4 (S $20^{\circ} 28^{\prime} 24,7$ ”, W $50^{\circ} 40^{\prime} 00,1^{\prime}$ ) distando 24,6 km da nascente, com predomínio de pecuária extensiva com dessedentação animal em alguns trechos; ponto 5 (S 20³0'48,9”; W 50³9' 14,7”) próximo à foz da microbacia, dista $29,4 \mathrm{~km}$ da nascente, trecho com pequenas e médias propriedades e uso da água para dessedentação animal (Figura 1).

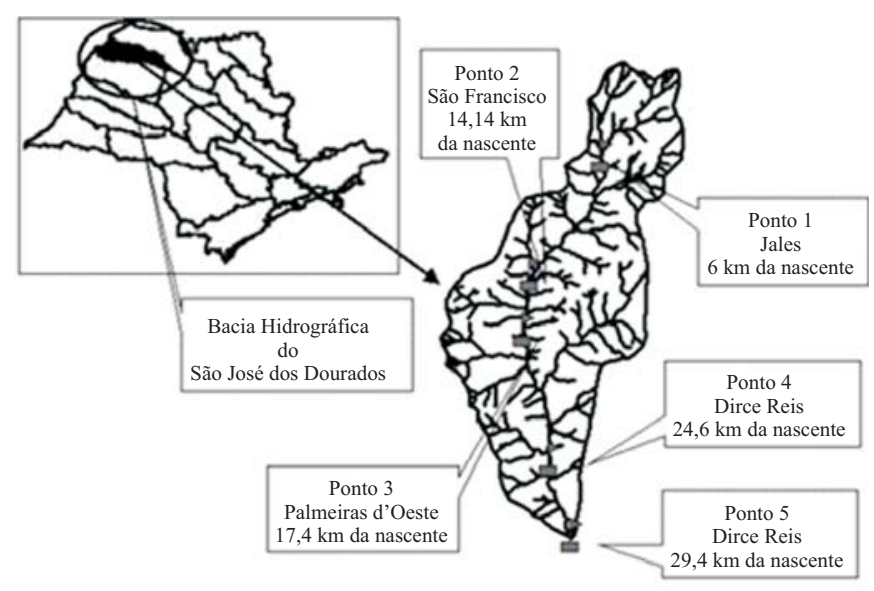

$\overline{\text { Figura 1. Microbacia do córrego do Coqueiro, pontos de amostragem e }}$ municípios

Coletaram-se as amostras de água em garrafas de polietileno de dois litros, higienizadas e lavadas com água destilada; depois de coletada a água, as garrafas foram acondicionadas em caixas de isopor com gelo e, posteriormente, levadas ao Laboratório de Hidráulica e Irrigação da UNESP Ilha Solteira. As variáveis analisadas neste estudo foram sólidos suspensos e dissolvidos, turbidez, condutividade elé- trica, pH, cálcio, magnésio, dureza e ferro total, a análise da qualidade da água obedeceu à metodologia e equipamentos descritos na Tabela 1.

A análise dos dados de qualidade de água consistiu na sua caracterização com base nos potenciais de dano aos sistemas de irrigação, conforme a Tabela 2. Para a caracterização da água utilizaram-se tabelas contendo dados de estatística descritiva (mínimo, máximo e média) e a distribuição dos resultados das análises (expressos em porcentagem do total das amostras) em cada classe de risco (baixo, médio e alto), por ponto e por parâmetro avaliado, de acordo com Vanzela (2004). Também se realizou análise de variabilidade espacial e temporal da qualidade de água, através de gráficos da variação dos parâmetros de qualidade de água (gráfico de linhas) e da precipitação acumulada entre os intervalos de avaliação (gráficos de barras), no decorrer do ano.

Tabela 2. Classificação empregada para fins de irrigação

\begin{tabular}{|c|c|c|}
\hline Problema & Parâmetro Avaliado & Classificação Utilizada \\
\hline $\begin{array}{l}\text { Dano aos sistemas de } \\
\text { irrigação }\end{array}$ & $\begin{array}{l}\text { Sólidos suspensos } \\
\text { e dissolvidos }\end{array}$ & Nakayama \& Bucks (1986) \\
\hline \multicolumn{3}{|c|}{ Ferro } \\
\hline \multicolumn{3}{|c|}{$\mathrm{pH}$} \\
\hline & Cálcio, magnésio e dureza & Ayres \& Westcot (1986) \\
\hline $\begin{array}{l}\text { Potencial de } \\
\text { salinização do solo }\end{array}$ & Condutividade elétrica & Ayres \& Westcot (1986) \\
\hline $\begin{array}{l}\text { Concentração de partículas } \\
\text { em suspensão na água }\end{array}$ & Turbidez & CONAMA (2005) \\
\hline
\end{tabular}

Os dados de qualidade de água, distribuídos entre o período seco e chuvoso, foram avaliados utilizando-se o valor médio das variáveis de qualidade da água em cada ponto de amostragem avaliado e o erro padrão da média, para se proceder à avaliação dos pontos de coleta. Definiram-se os períodos seco e chuvoso como os períodos de menor e maior precipitação acumulada, respectivamente, obtida entre os intervalos de avaliação. Adotou-se o critério de Gravetter \& Wallnau (1995) para diferenciar estatisticamente os tratamentos, indicado pela ausência de sobreposição dos limites superior e inferior dos valores da média \pm erro padrão. As análises estatísticas foram conduzidas utilizando-se o software SPSS 16.0 for Windows (SPSS, 2006).

A informação de precipitação é proveniente do Centro Integrado de Informações Agrometeorológicas do município

Tabela 1. Metodologia utilizada na análise de água

\begin{tabular}{|c|c|c|c|}
\hline Variáveis & Métodos & Equipamentos & Referências \\
\hline $\begin{array}{l}\text { Sólidos totais } \\
\text { Sólidos dissolvidos } \\
\text { Sólidos suspensos }\end{array}$ & Gravimétrico (mg L-1) & $\begin{array}{l}\text { Cápsula de porcelana, balança eletrônica de precisão } \\
\text { JK-200 da YMC C0, estufa } 305 \text { SE da Fanem, } \\
\text { dissecador e papel de filtro (poros de } 28 \mu \mathrm{m} \text { ) }\end{array}$ & Vanzela (2004) \\
\hline Turbidez & Nefelométrico (NTU) & Turbidímetro 2020 La Motte & APHA (1998) \\
\hline $\mathrm{pH}$ & peagâmetro & Peagâmetro Q-400 A da Quimis & APHA (1998) \\
\hline Condutividade elétrica & Eletrodo de platina $\mathrm{dS} \mathrm{m}^{-1}$ a $25^{\circ} \mathrm{C}$ & Condutivímetro Corning Pinacle & APHA (1998) \\
\hline Ferro total & Colorimétrico ferroespectral $\left(\mathrm{mg} \mathrm{L}^{-1}\right)$ & Colorímetro Hach & Vanzela (2004) \\
\hline Dureza total Cálcio Magnésio & Titulação $\left(\mathrm{mg} \mathrm{L}^{-1}\right)$ & Bureta e pipetas & Vanzela (2004) \\
\hline
\end{tabular}


de Jales (CIIAGRO, 2007) e a evapotranspiração estimada por Penman-Monteith (Allen et al., 1998), teve por base a estação automática localizada no município de Marinópolis e operada pela Área de Hidráulica e Irrigação da UNESP Ilha Solteira. O total de precipitação pluviométrica e evapotranspiração de referência para o período monitorado, foi de 1.138,2 e 1.819,4 mm, respectivamente; a vazão média para o período amostrado foi de $1.505,26 \mathrm{~m}^{3} \mathrm{~h}^{-1}$, com mínima de $126,21 \mathrm{~m}^{3} \mathrm{~h}^{-1}$ e máxima vazão de $3.762,62 \mathrm{~m}^{3} \mathrm{~h}^{-1}$.

\section{RESULTADOS E DISCUSSÃO}

Atributos Físicos: Sólidos suspensos, dissolvidos e turbidez

Na Tabela 3 se encontram os valores mínimos, máximos e médios, e a classificação das variáveis de sólidos suspensos e dissolvidos, de acordo com a classificação empregada para fins de irrigação (Nakayama \& Bucks, 1986). Os maiores valores de sólidos suspensos obtidos dentro da classificação de alto risco de dano ao sistema de irrigação localizada, foram os pontos 4 e 5, com uma amostra $(9,0 \%)$ e três amostras (27,2\%), respectivamente; no ponto 2 foram registradas seis amostras (60\%) e, no ponto 1, quatro amostras $(36,3 \%)$, na classificação de médio risco.

Tabela 3. Distribuição dos resultados de sólidos suspensos e dissolvidos de acordo com os padrões de qualidade de água para a irrigação na microbacia do córrego do Coqueiro, anos de 2006/2007

\begin{tabular}{|c|c|c|c|c|c|c|}
\hline \multirow[t]{2}{*}{ Parâmetro } & \multirow[t]{2}{*}{ Mínimo } & \multirow[t]{2}{*}{ Máximo } & \multirow[t]{2}{*}{ Média } & \multicolumn{3}{|c|}{$\begin{array}{c}\text { Potencial de dano ao sistema de } \\
\text { irrigação localizada }\end{array}$} \\
\hline & & & & Baixo & Médio & Alto \\
\hline $\begin{array}{l}\text { Sólidos } \\
\text { suspensos }{ }^{1}\end{array}$ & & $\mathrm{mg} \mathrm{L}^{-1}$ & & \multicolumn{3}{|c|}{ (\% das amostras) } \\
\hline Ponto 1 & 28,0 & 100,0 & 52,6 & 63,6 & 36,3 & 0,0 \\
\hline Ponto 2 & 1,0 & 57,0 & 36,6 & 40,0 & 60,0 & 0,0 \\
\hline Ponto 3 & 5,0 & 100,0 & 37,2 & 75,0 & 25,0 & 0,0 \\
\hline Ponto 4 & 22,0 & 186,0 & 60,3 & 72,7 & 18,1 & 9,0 \\
\hline Ponto 5 & 31,0 & 365,0 & 126,0 & 45,4 & 27,2 & 27,2 \\
\hline $\begin{array}{l}\text { Sólidos } \\
\text { dissolvidos }\end{array}$ & \multicolumn{3}{|c|}{$\mathrm{mg} \mathrm{L}^{-1}$} & \multicolumn{3}{|c|}{ (\% das amostras) } \\
\hline Ponto 1 & 54,0 & 126,0 & 120,0 & 100,0 & 0,0 & 0,0 \\
\hline Ponto 2 & 1,0 & 125,0 & 72,0 & 100,0 & 0,0 & 0,0 \\
\hline Ponto 3 & 64,0 & 113,0 & 106,0 & 100,0 & 0,0 & 0,0 \\
\hline Ponto 4 & 26,0 & 90,0 & 82,3 & 100,0 & 0,0 & 0,0 \\
\hline Ponto 5 & 71,0 & 131,0 & 117,0 & 100,0 & 0,0 & 0,0 \\
\hline
\end{tabular}

${ }_{1}$ Baixo $\left(<50 \mathrm{mg} \mathrm{L}^{-1}\right)$; médio (50-100 $\left.\mathrm{mg} \mathrm{L}^{-1}\right)$; alto $\left(>100 \mathrm{mg} \mathrm{L}^{-1}\right)$; ${ }^{2}$ baixo $\left(<500 \mathrm{mg} \mathrm{L}^{-1}\right)$; médio (500-2000 $\left.\mathrm{mg} \mathrm{L}^{-1}\right)$; alto (>2000 $\left.\mathrm{mg} \mathrm{L}^{-1}\right)$

Fonte: Nakayama \& Bucks (1986)

As concentrações de sólidos dissolvidos não foram elevados, ou seja, todas as amostras analisadas ficaram no potencial de baixo risco que possui concentração inferior a $500 \mathrm{mg} \mathrm{L}^{-1}$ segundo Nakayama \& Bucks (1986). As concentrações de sólidos suspensos e dissolvidos encontrados no decorrer desta pesquisa são semelhantes às obtidas por Vanzela (2004) e Fioravanti et al. (2004), no córrego Três Barras, que verificaram altas concentrações de sólidos suspensos com potencial de risco ao sistema de irrigação localizada e o restante das amostras coletadas se enquadrando dentro de baixo a médio risco. Almeida et al. (2007) também obtiveram, no Córrego do Boi, localizado na mesma região, altas concentrações de sólidos suspensos e de alto risco de dano à irrigação localizada. Em estudos experimentais em sistemas de irrigação localizada em que se utilizaram filtros para retenção de partículas foi observado que, para valores de até 20,0 $\mathrm{mg} \mathrm{L}^{-1}$ de sólidos suspensos, houve um aumento no número de retrolavagem dos filtros devido à perda de carga em função do volume filtrado (Ribeiro et al., 2005a).

A maior concentração de sólidos suspensos ocorreu na coleta do dia 22/03/2007, com valor máximo de 365,0 $\mathrm{mg} \mathrm{L}^{-1}$ no ponto 5, em virtude da influência da chuva dias antes da coleta. Os maiores valores médios de sólidos suspensos ocorreram no período chuvoso, sendo que os pontos 4 e 5 significativos, apresentaram ausência de sobreposição dos limites superior e inferior dos valores entre os períodos chuvoso e seco (Figura 2).

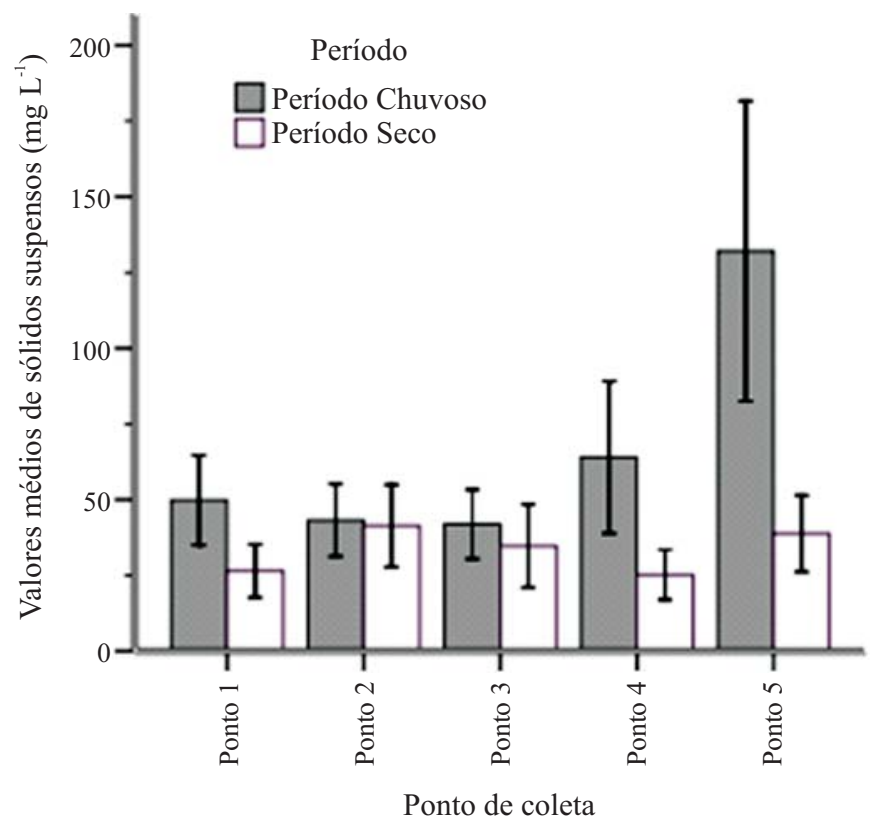

Figura 2. Valores médios de sólido suspensos por ponto de amostragem, na microbacia do córrego do Coqueiro, ano 2006/2007

Os aumentos na concentração de sólidos suspensos ocorrem, provavelmente, em razão da ausência de matas ciliares e do cultivo de pastagens degradadas em alguns trechos ao longo do córrego, favorecendo o transporte e a deposição de materiais sólidos (areia, silte, argila) além de detritos orgânicos de origem alóctone carreado por escoamento superficial, geralmente ocasionado pelas chuvas, fato este também observado por Hernandez \& Vanzela (2007) que relatam o processo de degradação da microbacia do córrego Três Barras, causado pelo assoreamento e lançamento de efluente de esgoto neste manancial. Neste sentido, devese adotar um monitoramento e o controle das atividades de pecuária (pastoreio intensivo em trechos de mata ciliar) e do desmatamento, além da implantação de reflorestamento com espécies nativas nos trechos ausentes de vegetação a fim de aumentar a capacidade de retenção de sedimentos e, conseqüentemente, reduzir o assoreamento do manancial e a erosão do solo. 
Um outro indicativo desses materiais na água pode ser observado nos valores de turbidez, que aumentaram durante o período chuvoso na amostra do mês de março, a qual supera o valor permitido pela resolução CONAMA (2005), para a Classe 2, que é de 100 NTU; na Figura 3 a diferença foi significativa entre os valores médios de turbidez, entre os períodos seco e chuvoso dos pontos 1, 3, 4 e 5; já no ponto 2 não houve diferença, sendo o ponto 5 com valores superiores no período chuvoso em relação aos pontos 1, 2 e 3; este ponto se situa em uma região de transição com características de lótico para semi-lótico, o qual favorece a retenção de uma concentração maior de sólidos em suspensão na água durante o período chuvoso, com valores médios de $126 \mathrm{mg} \mathrm{L}^{-1}$ de sólidos suspensos, sendo também influenciado pelo refluxo da água devido à entrada de água do rio São José dos Dourados pelo canal da foz do córrego do Coqueiro.

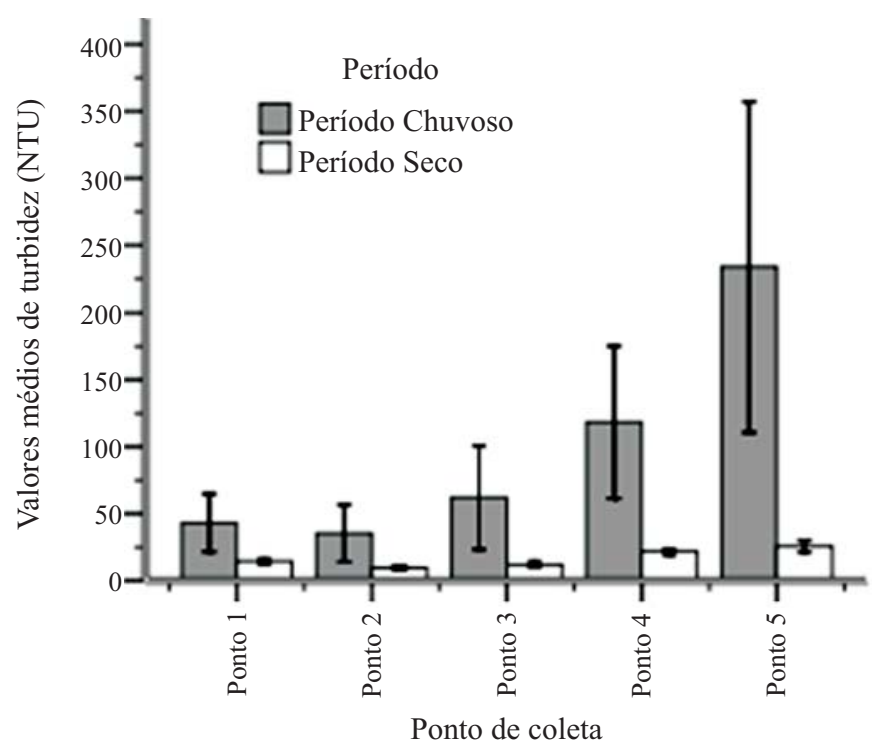

Figura 3. Valores médios de turbidez por pontos de amostragem, na microbacia do córrego do Coqueiro, ano 2006/2007

Atributos químicos: Cálcio, magnésio, dureza total, condutividade elétrica, $\mathrm{pH}$ e ferro

O valores de cálcio em todos os pontos analisados estão abaixo de $400 \mathrm{mg} \mathrm{L}^{-1}$, e o magnésios com apenas $25 \%$ das amostras do ponto 4 estão na classificação de risco alta de acordo com Ayres \& Westcot (1991). Em relação a classificação do dano potencial ao sistema de irrigação, na qual se verifica que a água deste manancial não oferece risco de dano ao sistema de irrigação não havendo, portanto, variação expressiva das concentrações ao longo do tempo.

O mínimo e o máximo valores de dureza total variaram entre $46 \mathrm{mg} \mathrm{L}^{-1}$ (ponto 5) e $160 \mathrm{mg} \mathrm{L}^{-1}$ (Ponto 1), respectivamente; as duas maiores médias de dureza total ficam entre $118 \mathrm{mg} \mathrm{L}^{-1}$ no ponto 1 e $117 \mathrm{mg} \mathrm{L}^{-1}$ no ponto 4 .

Vanzela (2004) obteve maiores concentrações de cálcio nas partes baixas do manancial, e concentração máxima de 196,0 $\mathrm{mg} \mathrm{L}^{-1}$, ainda que sem oferecer risco ao sistema de irrigação. As concentrações médias de cálcio e magnésio, ao longo do córrego do Coqueiro, são de 65,16 e 46,72 mg L ${ }^{-1}$, respectivamente; os valores de magnésio nos pontos 2, 3 e 5 apresentaram-se normais, abaixo de $60 \mathrm{mg} \mathrm{L}^{-1} \mathrm{e}$ o ponto 4 mostrou valores acima de $60 \mathrm{mg} \mathrm{L}^{-1}$ (três amostras) enquanto as demais amostras permaneceram na classificação normal; os níveis de concentração desses dois cátions no ambiente aquático provêm principalmente de solos do tipo argissolo vermelhos eutrófico e argissolo vermelho-amarelo eutrófico (EMBRAPA, 1999) existentes na microbacia, que são originados de rocha básica ou rica em minerais ferromagnesianos.

Os valores médios da concentração de magnésio e dureza total em todos os pontos avaliados, não foram significativos entre os períodos seco e chuvoso (Figura 4). O mínimo e o máximo valores de dureza total variaram entre $46 \mathrm{mg} \mathrm{L}^{-1}$

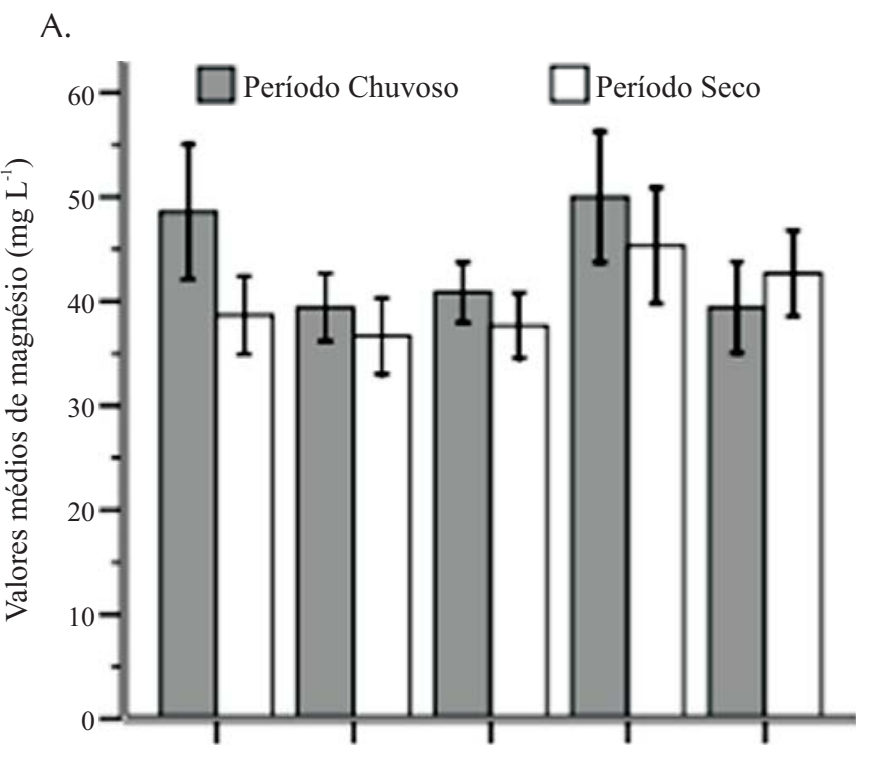

B.

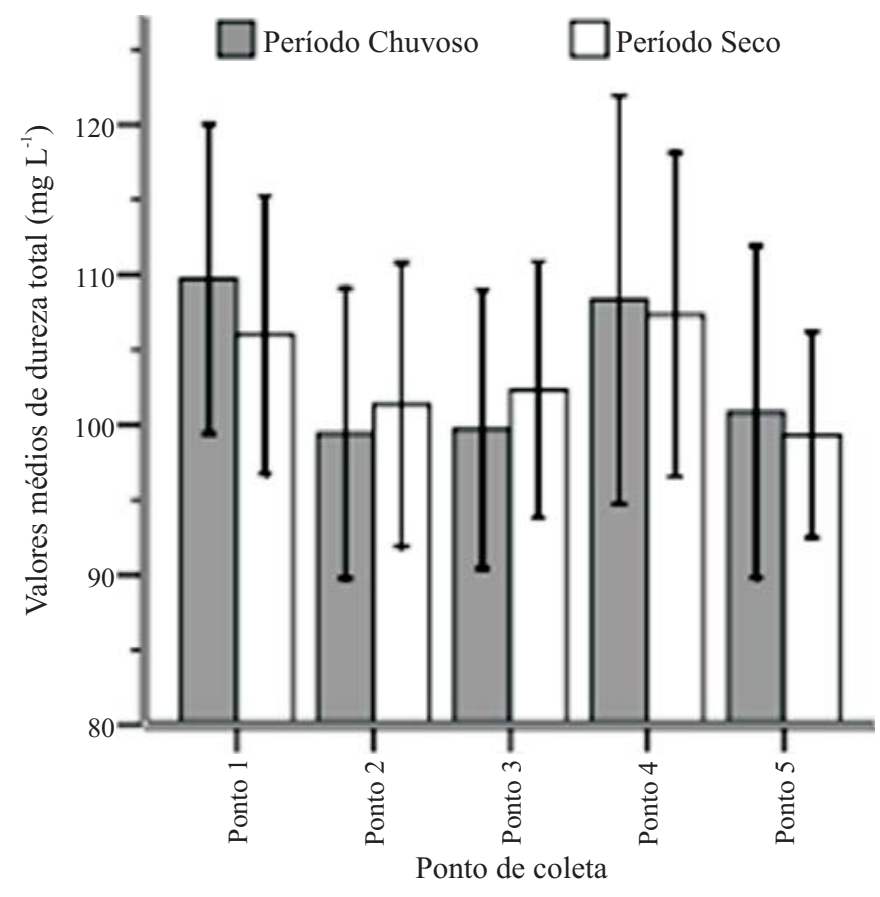

Figura 4. Valores médios da concentração de magnésio (A) e dureza total (B), na microbacia do córrego do Coqueiro, ano 2006/2007 
(ponto 5) e $160 \mathrm{mg} \mathrm{L}^{-1}$ (Ponto 1), respectivamente; as duas maiores médias de dureza total ficam entre $118 \mathrm{mg} \mathrm{L}^{-1}$ no ponto 1 e $117 \mathrm{mg} \mathrm{L}^{-1}$ no ponto 4. Para Allan (1995) e Esteves (1998), as concentrações desses íons são influenciadas pelos períodos de chuva e seca, características geológicas da bacia de drenagem e a ação antrópica no uso e ocupação dessas bacias hidrográficas.

Não há risco de salinização do solo considerando-se as análises da condutividade elétrica na água do córrego do manancial, os valores encontrados estão abaixo de $0,25 \mathrm{dS} \mathrm{m}^{-1}$ a $25{ }^{\circ} \mathrm{C}$ de acordo com a classificação utilizada por Ayres \& Westcot (1991); na análise da variação espacial e temporal da condutividade elétrica verifica-se diminuição nos valores na coleta do mês de março devido à precipitação que ocorreu um dia antes da coleta; entretanto, a partir do mês de junho os valores de condutividade elétrica começaram a aumentar e apresentam os valores mais elevados de condutividade elétrica ao final do período seco, ou seja, em outubro, sendo os valores de outubro de 2006 próximos aos valores de 2007; observa-se que a falta de precipitação pluviométrica, característica deste período seco e associado ao aumento da evapotranspiração, pode ser uma das causas de aumento dos valores de condutividade elétrica (Figura 5A). Os valores médios da condutividade elétrica não foram significativos entre os períodos seco e chuvoso em todos os pontos avaliados; entretanto, comparando-se os valores médios entre os pontos 1 e 4 em relação ao período chuvoso, observase que foram significativos (Figura 5B).

Outros fatores podem ter contribuído, como as características geopedológicas observadas em outras bacias do Estado (Souza \& Tundisi, 2000), o uso e ocupação da terra com a remoção da cobertura vegetal e a implantação de uma agricultura sem controle da erosão, o que pode favorecer o aumento do escorrimento superficial, carregando solos (íons, poluentes etc) que, ao longo do tempo, promovem o assoreamento dos rios e, conseqüentemente, pode elevar os valores de condutividade elétrica.

Segundo Esteves (1998) a condutividade elétrica pode informar concentração iônica e as diferenças geoquímicas de uma bacia hidrográfica e auxiliam a detectar fontes poluidoras nos ecossistemas aquáticos; a condutividade indica as modificações na composição de uma água, especialmente na sua concentração mineral mas não fornece nenhuma indicação das quantidades relativas dos vários componentes (CETESB, 2005)

Os valores de condutividade elétrica observados nesta microbacia devem ser, provavelmente, de origem geoquímica proveniente do solo, pois este manancial não possui lançamento de efluente de esgoto. Por outro lado, Vanzela (2004) obteve o máximo valor de condutividade elétrica no ponto 3, de 0,096 dS men , provavelmente devido a presença de uma estação de tratamento de esgoto. Argenton et al. (2004) relataram que os altos valores $\left(0,033 \mathrm{dS} \mathrm{m}^{-1}\right)$ de condutividade elétrica se devem ao lançamento de efluentes de esgoto da cidade de Itipapina, SP. No rio São José dos Dourados a condutividade média do ano de 2004 foi de 0,144 dS m-1 (CETESB, 2005), com médias próximas obtidas neste estudo.

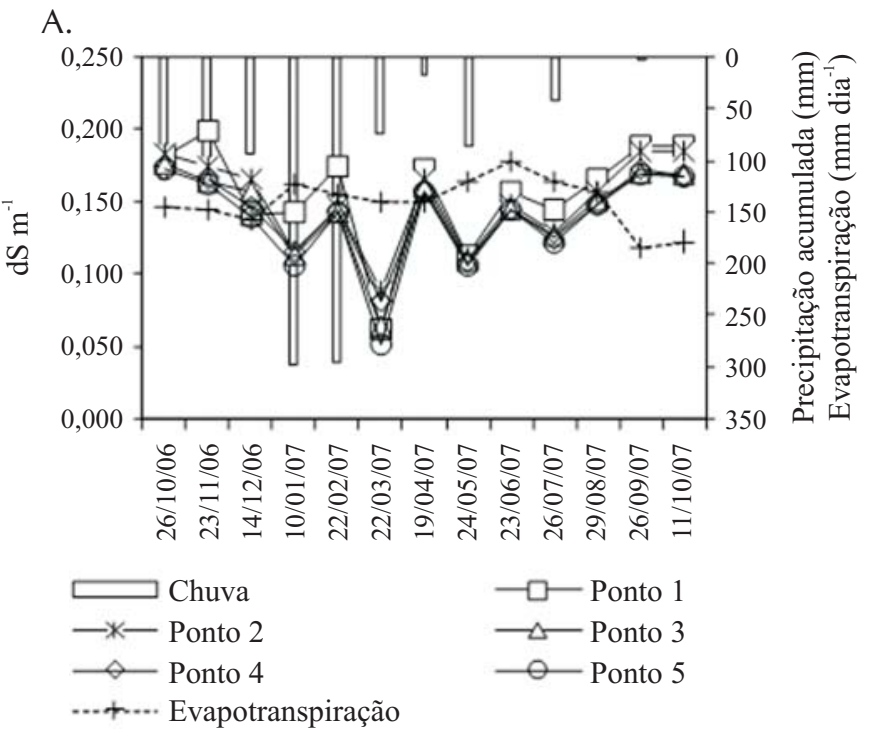

B.

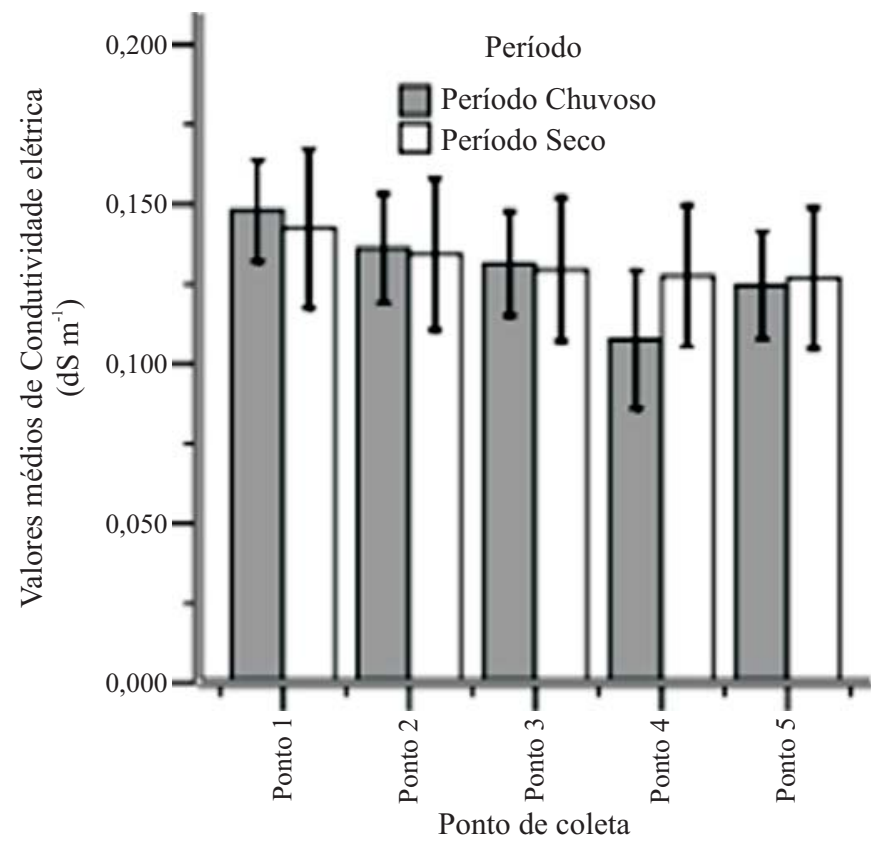

Figura 5. Variação espacial e temporal (A) e valores médios da condutividade elétrica (B) na microbacia do córrego do Coqueiro, ano 2006/2007

Os valores de $\mathrm{pH}$ no ponto 1 com $100 \%$ das amostras e os pontos de coleta 2, 3 e 5 com 92,3\% com risco médio de dano ao sistema de irrigação de acordo com a classificação de Nakayama \& Bucks (1986). O ponto 5 com apenas uma amostra analisada na classificação de alto risco, resultados corroborados em estudos semelhantes realizados por Vanzela (2004) e Ribeiro et al. (2005b), com maiores médias de pH entre 7,5 e 7,3, respectivamente. No município de Campinas, utilizando água de reservatório abastecido por uma represa, Ribeiro et al. (2004) evidenciou risco moderado de entupimento em sistema de irrigação por gotejamento, segundo a mesma classificação adotada nesta pesquisa e os valores variaram entre 6,88 a 7,39.

Observa-se, na Figura 6, que nos pontos de amostragem 4 e 5 os valores de $\mathrm{pH}$ foram significativos entre o período 
seco e chuvoso, sendo o período seco com maiores valores em relação ao período chuvoso e, de acordo com a Resolução CONAMA (2005), todas as amostras analisadas estão dentro dos limites para a Classe 2 que são de 6,0 a 9,0 os valores de $\mathrm{pH}$.

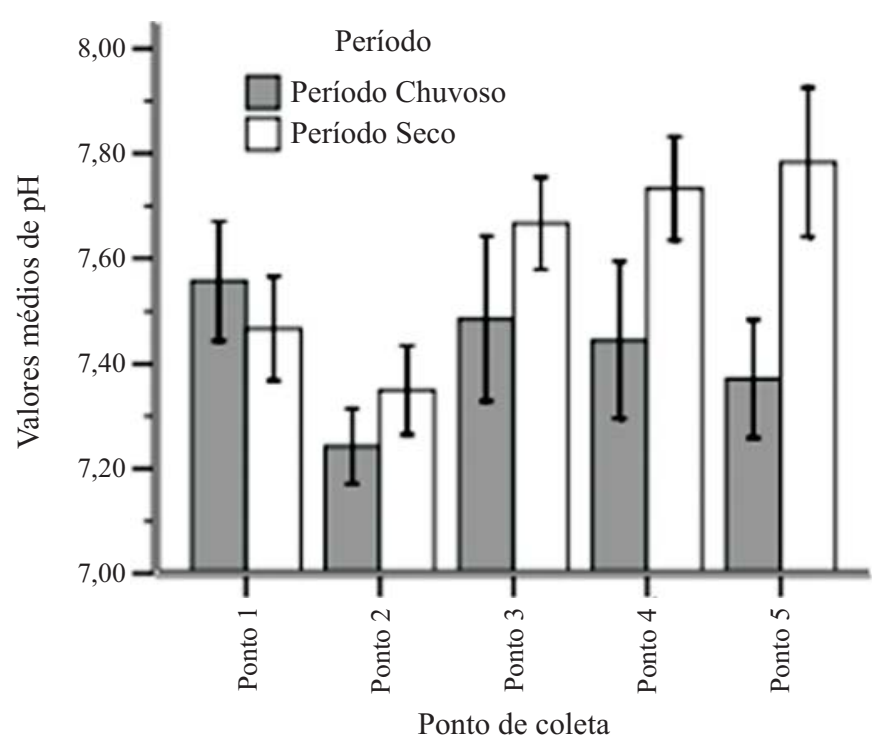

Figura 6. Valores médios de $\mathrm{pH}$ na microbacia do córrego do Coqueiro, ano 2006/2007

A presença de ferro em elevadas concentrações se caracteriza como o principal problema de qualidade de água em irrigação localizada e teve no oeste paulista o primeiro relato feito por Hernandez \& Petinari (1998) caracterizando uma situação de grave problema, representado pela obstrução de 58,4\% da área interna de uma tubulação após apenas 25 meses de uso, impregnada por 0,354 kg de material seco de elevada concentração de ferro por metro de tubo de $50 \mathrm{~mm}$.

Na Tabela 4 são apresentados os resultados obtidos, verificando-se que todos os pontos analisados estão na classificação de médio a alto potencial de dano à operação dos sistemas de microaspersão e gotejamento. Hernandez \& Petinari (1998) concluíram que águas com concentração superior a $0,5 \mathrm{mg} \mathrm{L}^{-1}$ quando utilizadas em sistemas de irrigação localizada merecem atenção especial dos projetistas e irrigantes.

Tabela 4. Concentração de ferro total e classificação na microbacia do córrego do Coqueiro, ano 2006/2007

\begin{tabular}{|c|c|c|c|c|c|c|}
\hline \multirow{3}{*}{$\begin{array}{l}\text { Parâmetro } \\
\text { Ferro Total } 1\end{array}$} & \multirow{2}{*}{ Mínimo } & \multirow{2}{*}{ Máximo } & \multirow{2}{*}{ Média } & \multicolumn{3}{|c|}{ Potencial de dano } \\
\hline & & & & Baixo & Médio & Alto \\
\hline & & $\mathrm{mg} \mathrm{L}^{-1}$ & & \multicolumn{3}{|c|}{ (\% das amostra) } \\
\hline Ponto 1 & 0,2 & 5,0 & 1,1 & 0,0 & 75,0 & 25,0 \\
\hline Ponto 2 & 0,2 & 3,7 & 0,69 & 0,0 & 91,6 & 8,3 \\
\hline Ponto 3 & 0,2 & 5,0 & 0,55 & 0,0 & 91,6 & 8,3 \\
\hline Ponto 4 & 0,3 & 5,0 & 0,9 & 0,0 & 66,6 & 33,3 \\
\hline Ponto 5 & 0,4 & 5,0 & 0,7 & 0,0 & 66,6 & 33,3 \\
\hline
\end{tabular}

${ }_{1}$ Baixo $\left(<0,2 \mathrm{mg} \mathrm{L}^{-1}\right)$; Médio $\left(0,2-1,5 \mathrm{mg} \mathrm{L}^{-1}\right)$; Alto $\left(>1,5 \mathrm{mg} \mathrm{L}^{-1}\right)$

Fonte: Nackayama \& Bucks (1986)
Os pontos de coleta 4 e 5 apresentaram amostras com valores acima de $1,5 \mathrm{mg} \mathrm{L}^{-1}$, com quatros amostras em cada ponto de coleta e valores acima do permitido (Nakayama \& Bucks, 1986). Ribeiro et al. (2005a) analisando a água superficial para fins de irrigação localizada encontrou situação de médio risco de obstrução dos emissores. Outros autores, como Ayres \& Westcot (1991) citam que o máximo valor da concentração de ferro permissível deveria ser de $0,5 \mathrm{mg} \mathrm{L}^{-1}$ mas, quando envolve os custos e a operação de filtragem do sistema de irrigação, esse valor máximo de ferro passa a ser de $2 \mathrm{mg} \mathrm{L}^{-1}$. A presença do elemento ferro em filtros em sistema de irrigação localizada, de acordo com Ribeiro et al. (2004) e Ribeiro et al. (2005a) ocasionaram perda de carga do sistema de filtragem e aumento no número de retrolavagem.

Esteves (1998) comenta a presença desse elemento nos corpos d'água e sua interação com bactérias filamentosas dos gêneros Gallionella e Leptothrix que oxidam o $\mathrm{Fe}^{+2}$, transformando-o em $\mathrm{Fe}^{+3}$ que, por sua vez, podem ser precipitados e o mesmo processo é possível de ocorrer nas tubulações do sistema de irrigação. Ford \& Tucker (1986), afirmam que água com concentração de ferro maior que $0,4 \mathrm{mg} \mathrm{L}^{-1}$ utilizada em sistema localizado, contribui para o desenvolvimento de bactérias férricas filamentosas que causam problemas de obstrução nos emissores e redução na uniformidade de aplicação de água no sistema de irrigação (Resende et al., 2001; Vieira et al., 2004).

No Estado de São Paulo a CETESB (2005) relatou que a presença de ferro-bactéria provoca o desenvolvimento de depósitos e contaminação biológica em canalizações da rede de distribuição de água para abastecimento público. Para outras regiões do país, no município de Lavras, Barcellos et al. (2006) encontrou em água superficial valores médios $1,24 \mathrm{mg} \mathrm{L}^{-1}$ de ferro total utilizada para consumo humano e agropecuário.

Todos os pontos de coleta, exceto o ponto 2, atingiram o máximo valor de $5 \mathrm{mg} \mathrm{L}^{-1}$ de ferro total; o aumento desta concentração foi observada na coleta do dia 22 de março antecedida por uma chuva de 70,4 mm que favoreceu o aumento da concentração deste elemento no sistema aquático (Figura 7A).

Como os solos do tipo argissolo que compõem essa bacia hidrográfica apresentam, em sua constituição, óxidos de ferro $\left(\mathrm{Fe}_{2} \mathrm{O}_{3}\right)$ (Prado, 1995) que, pela ação da enxurrada são lixiviados e podem ser levados para o leito do rio e contribuir com o aumento desse elemento na água, isto também pode ter ocorrido no Córrego Três Barras, com características pedológicas semelhantes (Vanzela, 2004) quando os altos valores aconteceram no período chuvoso; o mesmo se deu com Ribeiro et al. (2005a) com os valores médios de ferro total que aumentaram de 0,52 para $1,1 \mathrm{mg} \mathrm{L}^{-1}$, quando começou o período chuvoso e, em seguida, houve diminuição nos valores no período seco. Ribeiro \& Paterniani (2008) encontraram na captação de um sistema de irrigação localizada valor de $2,3 \mathrm{mg} \mathrm{L}^{-1}$ de ferro, e dentro do sistema de irrigação os valores ficaram entre 2,8 a 3,1 $\mathrm{mg} \mathrm{L}^{-1}$ devido a precipitação em conseqüência da oxidação deste elemento. Moura et al. (2007) obtiveram ao longo do 

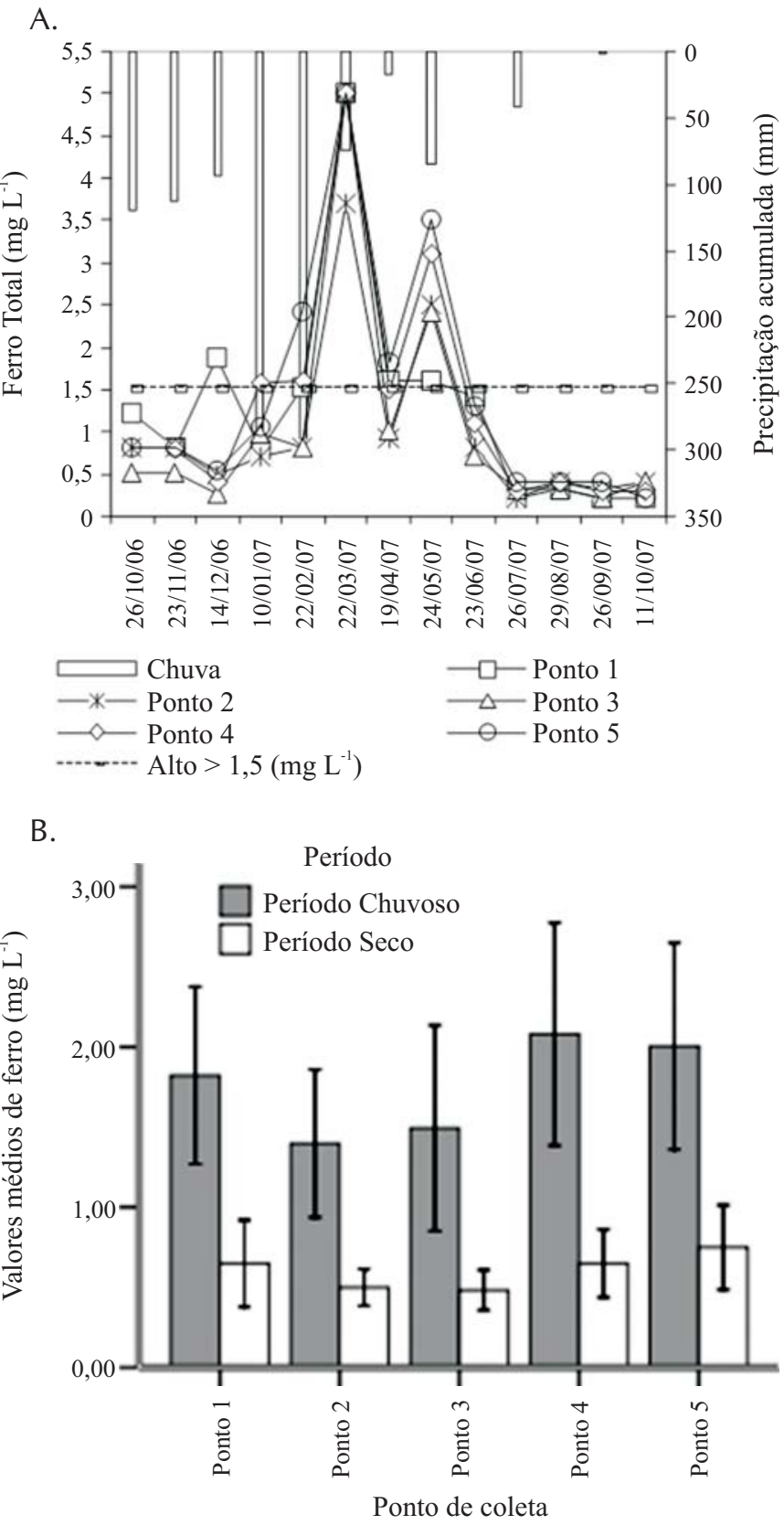

Figura 7. Variação espacial e temporal (A) e valores médios de ferro total (B), na microbacia do córrego do Coqueiro, ano 2006/2007

Córrego Três Barras, média de $1,0 \mathrm{mg} \mathrm{L}^{-1}$ de ferro total e risco médio de dano ao sistema de irrigação localizada, em manancial que recebe lançamento de efluentes de estação de tratamento de esgoto, que pode ter o aumento desse elemento na água. As análises desenvolvidas por Vanzela (2004) no efluente bruto e tratado de uma lagoa de tratamento de Marinópolis, revelaram concentração de até 9,6 mg L $\mathrm{m}^{-1}$ de ferro total. Como não há lançamento de esgoto no córrego do Coqueiro, a contribuição de ferro para esse manancial é oriundo do próprio solo que compõe a bacia de drenagem.

Para o uso da água na irrigação localizada deve-se atentar para o sistema de filtragem, tanto no dimensionamento inicial como no manejo adequado do sistema de irrigação, com a utilização de filtros na retenção de partículas sólidas e adaptação de aeradores para que o ferro oxide antes de entrar no sistema de irrigação.

\section{CONCLUSÕES}

1. Das variáveis físicas analisadas, as concentrações de sólidos suspensos na água de irrigação apresentaram classificação de médio a alto risco ao sistema de irrigação localizada.

2. O ferro total presente na água de irrigação foi o que apresentou risco de obstrução ao sistema de irrigação localizada, com 78,28 e 21,64\% das amostras analisadas no córrego do Coqueiro, na classificação de médio a alto risco ao sistema, respectivamente.

\section{LITERATURA CITADA}

Allan, D. J. Streams ecology: structure and function of runnig waters .School of Natural Resources and Environment, University of Michigan. 5.ed. Michigan: Springer, 1995. 388p.

Allen, R. G.; Pereira, L. S.; Raes, D.; Smith, M. Crop evapotranspiration - Guidelines for computing crop water requirements. Roma: FAO Irrigation and Drainage, 1998. 297p. Paper 56

Almeida, L. F.; Hernandez, F. B. T.; Franco, R. A. M. Qualidade física e biológica da água do córrego do boi para a irrigação, em aparecida d'Oeste, região noroeste do estado de São Paulo. In: Congresso Brasileiro de Engenharia Agrícola, 36, 2007, Bonito. Resumo... Bonito: CONBEA, 2007. CD Rom.

APHA - American Public Health Association; Water Work Association; Water Control Federation. Standard Methods for the examination of water and wastewater. 20.ed. New York: United Book, 1998. 1298p.

Argenton, E. C.; Espíndola, E. L. G.; Nogueira, A. M. Avaliação dos tributários da represa do Lobo (Itirapina/Brotas, SP): Uma abordagem ecossitêmica. In: Espíndola, E. L. G.; Wendland, E. (org.). Bacias hidrográficas: Diversas abordagens em pesquisas. São Carlos: Rima, 2004. cap.12, p.156-172.

Ayres, R. S.; Westcot, D.W. Qualidade de água na agricultura. Campina Grande: UFPB, 1991. 218p. Estudos FAO: Irrigação e Drenagem

Barcellos, C. M.; Rocha, M.; Rodrigues, L. S.; Costa, C. C.; Oliveira, P. R.; Silva, I. J.; Jesus, E. F. M.; Rolim, R. G. Avaliação da qualidade da água e percepção higiênico-sanitária na área rural de Lavras, Minas Gerais, Brasil, 1999-2000. Caderno de. Saúde Pública, v.22, n.9, p.1967-1978, 2006.

Braga, B.; Porto, M.; Tucci, C. E. M. Monitoramento de quantidade e qualidade das águas. In: Rebouças, A. C.; Braga, B.; Tundisi, J. G.(org.). Água doces no Brasil: Capital ecológico, uso e conservação. 3.ed., São Paulo: Escrituras Editoras, 2006. cap.5, p.145-160.

CETESB - Companhia Tecnológica de Saneamento Ambiental. Relatório de qualidades das águas interiores do estado de São Paulo 2004/CETESB. São Paulo: CETESB, 2005. 297p. 
CIIAGRO - Centro Integrado de Informações Agrometeorológicas. Dados climáticos. Instituto Agronômico de Campinas. http://www.ciiagro.sp.gov.br/20 Set. 2007.

CONAMA - Conselho Nacional de Meio Ambiente. Resolução de n.357/2005. http:www.mma.gov.br/port/conama/res/res05/ res35705.pdf. 20 Abr.2007.

EMBRAPA - Empresa Brasileira de Pesquisa Agropecuária. Sistema Brasileiro de Classificação de Solos. Rio de Janeiro: EMBRAPA, 1999.412p.

Esteves, F. A. Fundamentos de limnologia. Rio de janeiro: Interciência/FINEP, 1998. 575p.

Fioravanti, C. D.; Vanzela, L. S.; Mauro, F.; Gomes, D. R.; Hernandez, F. B. T. Diagnóstico da qualidade de água para a irrigação do córrego Três Barras no município de Marinópolis SP. In: Congresso Brasileiro de Engenharia Agrícola, 33, 2004, São Pedro. Resumos ... São Pedro: SBEA, 2004. CD Rom.

Ford, H. A.; Tucker, D. P. H. Clogging of drip systems from metabolic products of iron and sulfur bacteria. International Drip Irrigation. Congress, Proceedings... San Diego. 1986 p.212-214.

Gravetter, F. J.; Wallnau, L. B. Statistics for the behavioral sciences. 2.ed. St. Paul: West Publishing, 1995. 429p.

Hernandez, F. B. T.; Petinari, R. A. Qualidade da água para irrigação localizada. In: Congresso Brasileiro de Engenharia Agrícola, 27, 1998, Poços de Caldas, Anais...Poços de Caldas: SBEA, 1998, v.II, p.58-60.

Hernandez, F. B. T.; Souza, S. A. V. de; Zocoler, J. L.; Frizzone, J. A. Simulação e efeito de veranicos em culturas desenvolvidas na região de Palmeira d'Oeste, estado de São Paulo. Engenharia Agrícola, v.23, n.1, p.21-30, 2003.

Hernandez, F. B. T.; Vanzela, L. S. Transporte de sedimento na microbacia do córrego Três Barras, Marinópolis, SP. In: Congresso Brasileiro de Engenharia Agrícola, 36, 2007, Bonito. Resumos... Bonito: CONBEA, 2007. CD Rom.

Moura, R. S.; Hernandez, F. B. T.; Vanzela, L. S. Monitoramento da qualidade química da água para fins de irrigação no córrego Três Barras, Marinópolis - SP. In: Congresso Brasileiro de Engenharia Agrícola, 2007, Bonito. Resumos... Bonito: SBEA, 36, 2007. CD Rom.

Nakayama, F. S.; Bucks, D. A. Trickle irrigation for crop production. St. Joseph: ASAE, 1986. 383p.

Pereira, A. R.; Angelocci, L. R.; Sentelhas, P. C. Agrometeorologia: fundamentos e aplicação prática. Guaíba: Agropecuária, 2002. 478p.

Prado, H. de. Manual de classificação de solos do Brasil. 2.ed. Jaboticabal: FUNEP, 1995. 197p.

Resende, R. S.; Casarini, E.; Folegatti, M. V.; Coelho, R. D. Ocorrência de entupimento de origem biológica em sistema de irrigação por gotejamento. Revista Brasileira de Engenharia Agrícola e Ambiental, v.5, p.156-160, 2001.
Ribeiro, T. A. P.; Airoldi, R. P. da Silva; Paterniani, J. E. S.; Silva, M. J. M. O efeito da qualidade da água no entupimento de emissores e no desempenho de filtros utilizados na irrigação por gotejamento. Irriga, v.9, n.2, p.136-149, 2004.

Ribeiro, T. A. P.; Airoldi, R. P. Silva; Paterniani, J. E. S.; Silva, M. J. M. Efeito da qualidade da água na perda de carga em filtros utilizados na irrigação localizada. Revista Brasileira Engenharia Agrícola e Ambiental, v.9, n.1, p.1-6, 2005a.

Ribeiro,T. A. P.; Paterniani, J. E. S. Microaspersores entupidos devido a problemas de ferro na água. Ciência Rural, v.38, n.5, p.1456-1459. 2008.

Ribeiro, T. A. P.; Paterniani, J. E. S.; Silva, Airoldi, R. P. S.; Silva, M. J. M. Water quality and head loss in irrigation filters. Scientia Agricola, Piracicaba, v.61, n.6, p.563-572. 2004.

Ribeiro, T. A. P.; Paterniani, J. E. S.; Silva, Airoldi, R. P. S.; Silva, M. J. M. Variação dos parâmetros físicos, químicos e biológicos da água em um sistema de irrigação localizada. Revista Brasileira Engenharia Agrícola e Ambiental, v.9, n.3, p.295-301, 2005b.

Rodrigues, R. R. Florestas Ciliares? Uma discussão nomenclatural das formações ciliares. In: Rodrigues, R. R.; Leitão Filho, H. F. (ed.) Matas Ciliares: Conservação e recuperação. São Paulo: Universidade de São Paulo/FAPESP, 2000. cap.6, p.91-99.

SEMA - Secretaria Estadual de Meio Ambiente. Relatório de Qualidade Ambiental do Estado de São Paulo - informações referentes a 2005. São Paulo, 2006. http:// www.ambiente.sp.gov.br/relatorio_ambiental/2005_2006/ index.html. 10 Mar. 2007.

Souza, A. D. G.; Tundisi, J. G. Hidrogeochemical comparative study of the Jaú and Jacaré-Guaçú river watersheds, São Paulo, Brazil. Revista Brasileira Biologia, v.60, n.4, p.563-570, 2000.

SPSS. SPSS for windows versions 16.0. http://www.spss.com. 10 Mar. 2006.

Tundisi, J. G.; Tundisi, M. T.; Abe, D. S.; Rocha, O; Starling, F. Limnologia de águas interiores: impactos, conservação e recuperação de ecossistemas aquáticos. In: Rebouças, A. C.; Braga, B.; Tundisi, J. G. (Org.). Águas doces no Brasil: capital ecológico, uso e conservação (3.ed.). São Paulo: Escrituras Editoras, cap.7, 2006. p.203-240.

Vanzela, L. S. Qualidade de água para irrigação na microbacia do córrego Três Barras no município de Marinópolis, SP. Ilha Solteira: UNESP, 2004. 96p. Dissertação Mestrado

Vieira, G. H. S.; Mantovani, E. C.; Silva, J. G. F.; Ramos, M. M.; Silva, C. M. Recuperação de gotejadores obstruídos devido à utilização de águas ferruginosas. Revista Brasileira de Engenharia Agrícola e Ambiental, v.8, n.1, p.1-6, 2004. 